\title{
Enlightenment of Rotterdam Port to the Construction of Inland International Logistics Hub under the Framework of Chongqing Free Trade Zone
}

\author{
Yifei Gong, Peiyue $\mathrm{Li}^{*}$ \\ College of Economic and Management, Southwest University, Chongqing, China \\ Email: ^gyifei@swu.edu.cn
}

How to cite this paper: Gong, Y. F., \& Li, P. Y. (2020). Enlightenment of Rotterdam Port to the Construction of Inland International Logistics Hub under the Framework of Chongqing Free Trade Zone. Technology and Investment, 11, 46-57.

https://doi.org/10.4236/ti.2020.113004

Received: May 5, 2020

Accepted: June 27, 2020

Published: June 30, 2020

Copyright $\odot 2020$ by author(s) and Scientific Research Publishing Inc. This work is licensed under the Creative Commons Attribution International License (CC BY 4.0).

http://creativecommons.org/licenses/by/4.0/

\begin{abstract}
The establishment of Chongqing Free Trade Zone will bring a new opportunity to the construction of Chongqing inland international logistics hub, and it also faces many challenges. In order to speed up the construction of Chongqing inland international logistics hub, it is necessary to learn from the successful experience of Rotterdam Port in the Netherlands. Based on the analysis of the problems existing in the construction of the hub under the framework of Chongqing Free Trade Zone, this paper draws lessons from the successful experience of Rotterdam Port in the Netherlands and put forward countermeasures and suggestions for the construction of Chongqing inland international logistics hub.
\end{abstract}

\section{Keywords}

Free Trade Zone, Inland International Logistics Hub, Rotterdam Port

\section{Research Background}

At present, China is in the key stage of promoting high-quality economic development and building a new pattern of high-level opening up to the outside world. In order to ensure the stable operation and high-quality development of our economy, it is imperative to promote the high-quality development of trade. In March 2017, the State Council issued the general plan of the China Pilot Free Trade Zone in seven regions including Chongqing.

As a free trade zone, its competitiveness increasingly depends on logistics ability. Therefore, putting the development of logistics industry in the first place 
is an urgent need for Chongqing Free Trade Zone to cope with economic globalization and improve competitiveness, which is conducive to economic development and improve the quality of operation of the Free Trade Zone. There is an urgent need to contribute to economic development and improve the quality of the free trade zone. In 2019, President Xi Jinping stressed in his inspection of Chongqing that Chongqing should strive to play a supporting role in promoting the development of the western region in China in the new era, play a leading role in advancing the co-construction of the "The Belt and Road", and play an exemplary role in promoting the green development of The Yangtze River Economic Zone. Chongqing is required to "accelerate the construction of a large channel for going abroad and build an inland international logistics hub support", "make new contributions to accelerate the formation of the pattern of the opening up of land-sea internal and external linkage and east-west mutual aid". Under the background of "The Belt and Road" strategy and The Yangtze River Economic Zone strategy being put forward successively, Chongqing is focusing on building inland international logistics hub and port highland.

\section{Problems in the Construction of Inland International Logistics Hub under the Framework of Chongqing Free Trade Zone}

\subsection{Introduction of Chongqing Free Trade Zone}

The China (Chongqing) Pilot Free Trade Zone was approved by the State Council on March 15, 2017 to establish the experimental zone, and was established on April 1, with an implementation scope of 119.98 square kilometers, covering three areas: Liangjiang Area, Xiyong Area and Guoyuan Port Area. By the end of July 2019, there were 29,287 newly registered enterprises (including branches) in Chongqing Free Trade Zone, with a registered capital of more than 292.8 billion yuan, 2225 projects introduced in the whole region, and a signed contract amount of 627.123 billion yuan. As of October, Chongqing Free Trade Zone has accumulated 197 institutional innovation achievements, and 12 experiences and cases, such as railway bill of lading letter of credit financing settlement, new mode of knowledge value credit financing, and big data platform for comprehensive market supervision, have been copied and promoted nationwide (Li, 2017).

\subsection{Advantages of Chongqing in Building an Inland International Logistics Hub}

\subsubsection{Advantages of Location and Channel Construction}

As the only municipality directly under the Central Government in the Midwest, Chongqing is at the "Y" zigzag link point between "The Belt and Road" and The Yangtze River Economic Zone, which is an important strategic fulcrum to promote the development of the western region. Although located inland, the framework of Chongqing inland international logistics hub has taken shape. At 
present, Chongqing has basically established five major international logistics channel systems: east, west, south, north and aviation.

\subsubsection{The Comprehensive Transportation System Is Improving}

Chongqing is located in the golden waterway of the Yangtze River, and basically built the waterway system of "one trunk and two branches". In the first half of 2019, its inland ports completed cargo throughput of 83.79 million tons, ranking the eighth inland river ports in the country (see Table 1). At present, among the three major hub ports planned by Chongqing, in addition to Guoyuan Port, Wanzhou Xintian Port and Fuling Longtou Port are in the process of planning the construction of railways to enter the port. After the completion of these projects, the cargo throughput of Chongqing Inland Port is expected to further improve in the country.

In terms of railways, Chongqing has formed a "one hub and ten main lines" railway network, with a mileage of 2371 kilometers. It is worth mentioning that the east ring line of Chongqing railway hub under construction will unite the six major logistics ports and ports, and effectively connect nine parks, which will help improve the efficiency of cargo collection and distribution and reduce logistics costs (see Figure 1).

In terms of airport, the preliminary work of T3B terminal and the fourth runway of Jiangbei Airport has been started successively. After completion, it can meet the annual cargo throughput of 3 million tons. In addition, the preparatory work for the second international airport and Rongchang Cargo Airport has started. After the landing of Rongchang Cargo Airport, it will help seize the first opportunity of the layout of cargo airports in the western region and play an important role in enhancing Chongqing's agglomeration and radiation.

In terms of expressways, Chongqing is vigorously implementing the three-year action plan for expressways, complementing the shortcomings of the highway's external gathering and transportation network, strengthening the construction of channels, and strengthening the channel connection with expressways in surrounding areas, accelerating the expansion project of the ray expressway

Table 1. Rank of cargo throughput of national inland port from January to June $2019^{\mathrm{a}}$.

\begin{tabular}{cccc}
\hline Rank & Port & January-June (10,000 tons) & Year-on-year increase (\%) \\
\hline 1 & Suzhou Port & 26,250 & 0.0 \\
2 & Zhenjiang Port & 15,064 & 106.3 \\
3 & Nantong Port & 14,921 & 23.4 \\
4 & Taizhou Port & 13,824 & 10.9 \\
5 & Nanjing Port & 12,590 & 5.8 \\
6 & Jiangyin Port & 10,609 & 4.2 \\
7 & Chongqing Port & 8379 & 8.7 \\
8 & Wuhu Port & 5887 & 24.3 \\
\hline
\end{tabular}

a Source: http://www.chinaports.com/. 


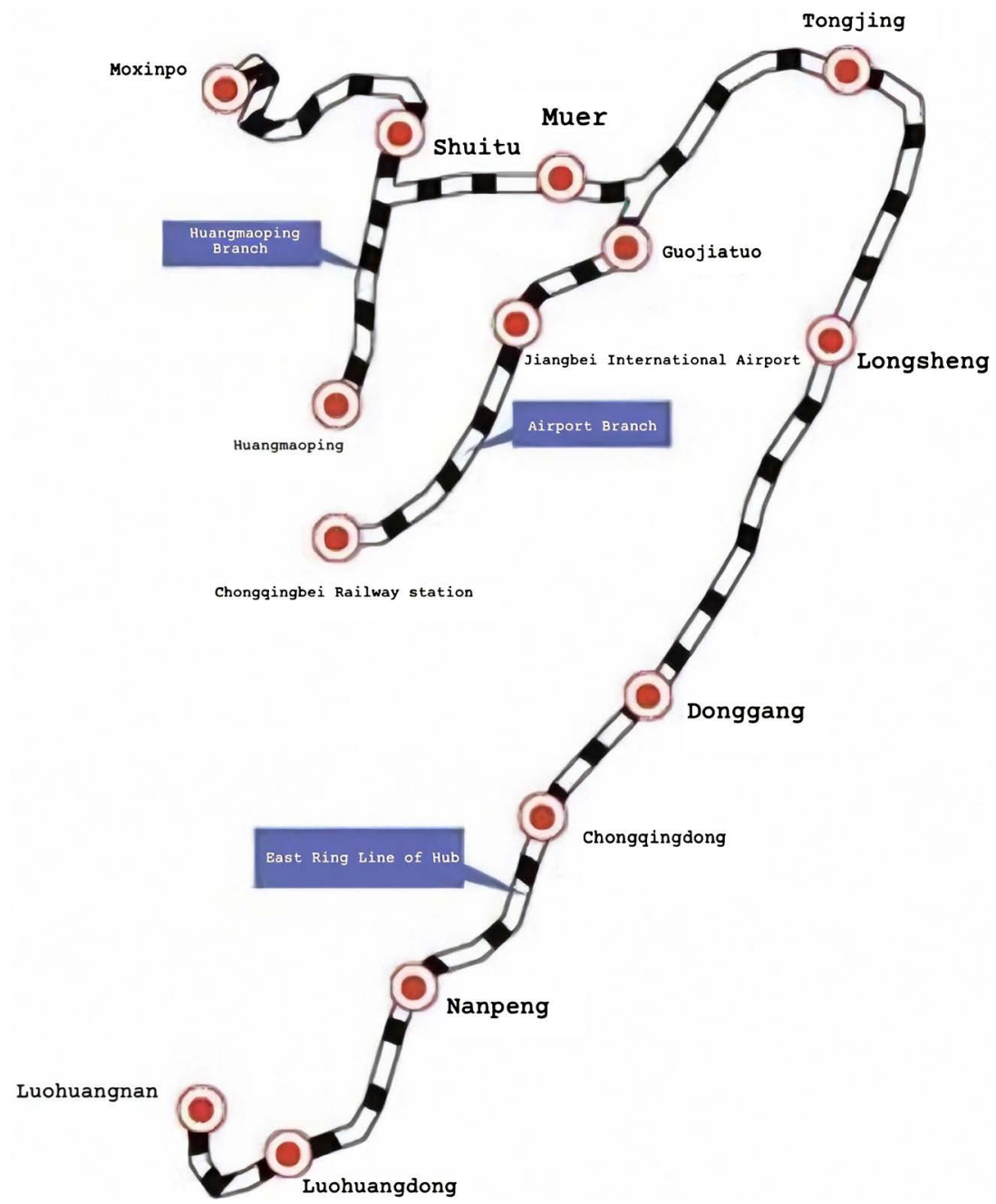

Figure 1. Schematic diagram of the east ring line of Chongqing railway hub.

channels, and greatly improving the traffic capacity of the ray expressway.

\subsubsection{Open Platform Is Relatively Complete}

At present, Chongqing has one state-level new areas of Liangjiang New Area, two open platforms of Free Trade Area and The China-Singapore Demonstration Initiative, seven national-level High-tech Industrial Development Zones and Economic and Technological Development Zones, four first-class ports and multiple special customs supervision areas, etc.

\subsection{Problems in the Construction of Chongqing Inland International Logistics Hub}

\subsubsection{Logistics Facilities Are Scattered}

Although Chongqing has complete roads, railways, waterways, aviation logistics nodes and facilities, logistics facilities are scattered. The main logistics facilities, such as Western Logistics Park, Cuntan Port, Guoyuan Port, Jiangbei International Airport, Ba'nan Highway Logistics Base, Xiaonanya Railway Logistics Center and other major logistics facilities, are scattered in many regions of 
Chongqing, with an average transportation distance of about 50 kilometers, of which the Midwest Logistics Park is 32 kilometers from Cuntan Port and more than 50 kilometers from Jiangbei International Airport. Each logistics social practice operation subjects are diverse, and the cooperation among them is not high, which leads to the poor connection of goods among different facilities, long conversion time and high cost, and it is difficult to drive the aggregation of logistics industry, and the logistics joint force is difficult to develop.

\subsubsection{Low Level of Logistics Information Platform Construction}

The construction of various logistics information platforms in Chongqing is incomplete, there is no mature intermodality platform, the information flow of intermodality is not smooth, and there is a lack of unified coordination. Various logistics information resources have not been integrated, resulting in waste of logistics resources and low customs clearance efficiency of goods. There are Chongqing Intelligent Logistics Public Information Platform, Chongqing Shipping Exchange and Chongqing Electronic Port Information System Logistics Information Platform. Chongqing Intelligent Logistics Public Information Platform has more mature modules for road freight information matching and TMS management (Hu, 2018); Chongqing Shipping Exchange mainly deals with information matching of shipping capacity and source of goods, involving a relatively single mode of transportation; Chongqing Electronic Port intermodality module is still being tested, and the function still has room for expansion (Chen, 2019).

\subsubsection{Lack of Professional Logistics Talents}

The comprehensive function of Free Trade Zone determines the complexity of its international logistics business. Therefore, the lack of professional logistics talents is a major problem in the construction of inland international logistics hubs. The logistics staff must have a higher comprehensive quality, especially the addition of some high-tech makes the logistics business of Free Trade Zone need some high-quality compound talents to work. However, the knowledge structure of talents in the past has been unable to cultivate such talents, which has led to bottlenecks in the construction of inland international logistics hubs under the framework of Free Trade Zone. The cultural quality of logistics practitioners in Chongqing Free Trade Zone is generally low, and there is an extreme shortage of multiple technical talents with logistics, finance, and management. The shortage of talents will lead to a slowdown in the construction of Chongqing inland international logistics hub, while the shortage of logistics talents and the imbalance of the vigorous development of the logistics industry will not be conducive to Chongqing's trade with other countries.

\section{Analysis of the Successful Experience of Rotterdam Free Trade Port in the Netherlands}

Rotterdam Port is located at the confluence of Rhine River and Maas River, with 
an area of more than 80 square kilometers and an annual throughput of more than 400 million tons. According to statistics, in 2017, Rotterdam port completed cargo throughput of 467 million tons and container throughput of 13.7 million TEU (see Figure 2), an increase of about 30\% compared with 2007. As the largest port in Europe and one of the most important logistics centers in the world, the successful experience of the Rotterdam Port is of great significance for accelerating the construction of inland international logistics hub under the framework of Chongqing Free Trade Zone.

\subsection{Vast Economic Hinterland}

The development of Rotterdam Port is closely related to the development of hinterland economy. The neighboring countries, such as Germany, Switzerland, France, Belgium, and the United Kingdom, have developed industries. The raw materials and fuels needed by these countries to develop industries mainly rely on imports, and the products they produce are to be exported, so that Rotterdam Port, which is in their middle position and has good transit conditions, becomes a transit centre for their bulk goods. Not only that, Rotterdam Port is an important port connecting five continents: Asia, Africa, Europe, the United States and Australia, which has been called the "European Gateway" since ancient times (Deng, 2017). Shippers and shipowners from all over the world regard the Rotterdam Port as the first port to enter Europe, and hundreds of millions of tons of goods are transferred to Europe and even around the world in Rotterdam Port every year through a perfect and fast inland shipping, railway, offshore, highway and other transportation networks.

\subsection{Preferential and Convenient Policies}

The Netherlands is based on free trade and has always adopted an open, inclusive and friendly policy. In terms of trade facilitation, the Netherlands has established a large number of bonded warehouses and provides tax exemption or

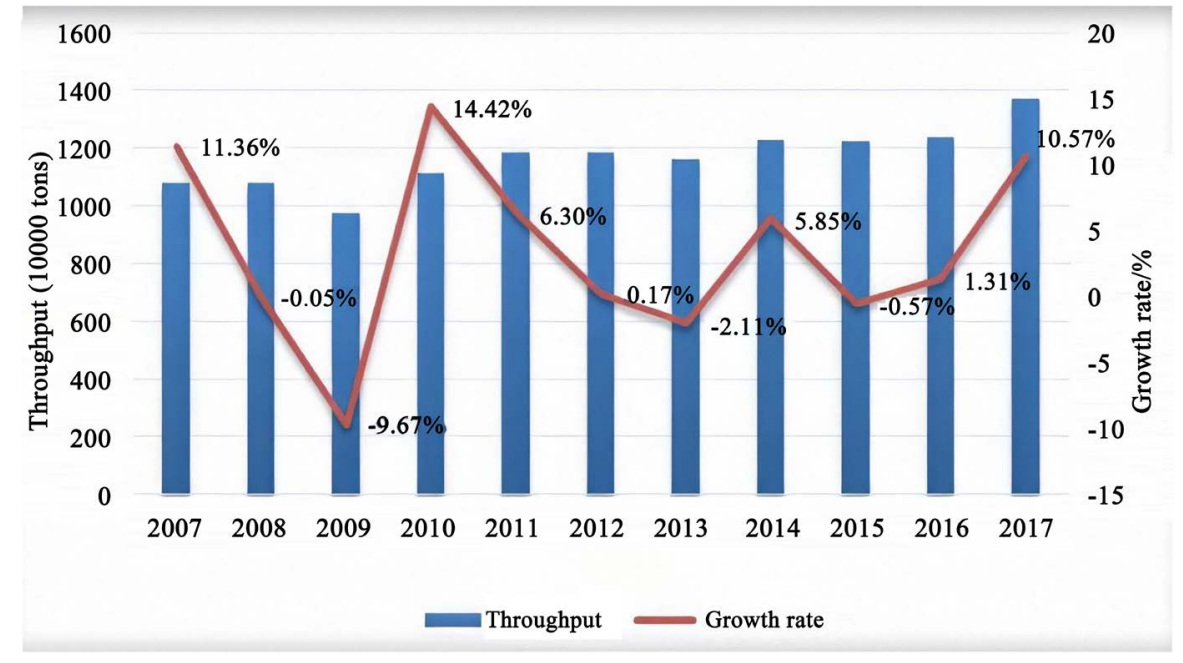

Figure 2. Throughput of Rotterdam Port in 2007-2010. 
deferred payment for imported goods. In addition, the Dutch Customs has issued relevant policy support for the processing of imported and exported goods. In terms of investment incentives, foreign investment in the Netherlands basically has no industry or approval restrictions. The threshold for registering enterprises in the Netherlands is low and the procedure is simple, which can be completed in a few days. Foreign-funded enterprises in the Netherlands enjoy national treatment and are not discriminated against in government procurement, public bidding and entrepreneurial innovation support projects, etc. In addition, the Netherlands provides good services for enterprises. In terms of financial liberalization, the Netherlands has implemented loose foreign exchange management measures. The remittance of legal income of foreign-funded enterprises is not subject to any restrictions, and foreign investors can choose any currency as the payment currency. Foreign investors can open other foreign exchange accounts in the Netherlands without restrictions on foreign exchange management. In addition, foreign enterprises enjoy national treatment (Wang \& Chen, 2018).

\subsection{Complete Infrastructure}

Rotterdam has made huge investments in infrastructure, with billions of funds spent on expanding the railway network and improving the traffic capacity of the 45-kilometer highway between Maasvlakte and Hinterland. Many projects that need to be built also include the modernization and upgrading of the old port area, so the investment of Rotterdam Port in port infrastructure construction will remain at a high level in the future. For a long time, the port authority of Rotterdam Port had a broader understanding of infrastructure construction, and had also practiced it. One example is the use of big data in the accessibility and opening up of the port area. With the integration of multiple information streams, the Rotterdam Port can go further in the improvement and expansion of services and infrastructure.

\subsection{Pay Attention to the Application of Information Technology}

Rotterdam Port is committed to promoting the process of port digitalization, focusing on improving the efficiency and service level of port operations through the application of modern information technology and artificial intelligence technology. One is to establish a complete information infrastructure. Using LAN, cloud computing, mobile terminal equipment, IOT, GIS, video monitoring system to provide basic support for digital and network management of port areas, wharf, yards and port logistics. The second is to establish a port operation management CITOS system to realize the seamless connection between the information system instructions and the control functions of the terminal machinery and equipment, so that various port resources can be efficiently and reasonably allocated and dispatched. The third is to establish an interconnected information platform Portbase System, continue to strengthen the advantages of 
the hinterland transportation network, integrate related port services, open up the data flow of the upstream and downstream links of the port value chain, and promote government functional departments, shipping companies, logistics companies, financial and legal service institutions for efficient operation. The fourth is to establish a port big data center, realize centralized and unified management of port value chain information resources, carry out innovative applications such as big data-based infrastructure construction, production management, customer service, market forecast and so on, and provide timely, accurate and standardized data services for relevant parties.

\subsection{Pay Attention to the Training of High-Quality Logistics Talents}

Due to its small territory, the Dutch government attaches great importance to the education of trade and logistic. In teaching, more attention is paid to the future development trend of international logistics. Through various forms of courses, students can acquire practical logistics knowledge and skills. From market, management, trade, customs, distribution, warehousing, sea, land and air transportation, cost control, commodity science and so on, to create every excellent international logistics elite. The major educational institutions in Rotterdam are also actively carrying out research and education related to maritime transport, and working with people from all walks of life to build a future-oriented modern port (Wang \& Chen, 2018).

\section{The Enlightenment of the Successful Experience of Rotterdam Free Trade Port in the Netherlands to Chongqing}

\subsection{Plan Top Level Design}

To do a good job, first of all, there must be top level design. Chongqing's construction of inland international logistics hub can draw lessons from the construction of the Rotterdam Port in the Netherlands, so as to carry out innovation and sustainable development. From the design, the Rotterdam Port has positioned it as a leading logistics center in Europe and even internationally. To build an inland international logistics hub, Chongqing should first do a top level design from the aspects of strategy, technology and implementation, plan the overall pattern of the inland international logistics hub, clear construction objectives, main tasks, technical paths and key breakthrough directions, and formulate detailed implementation plans and action plans. Strengthen the guidance of strategic planning and promote the construction of inland international logistics hubs in an integrated and orderly manner.

\subsection{Strengthen Policy Support and Guidance}

The success of the Rotterdam Port in the Netherlands cannot be separated from the support of the government. The construction of Chongqing inland international logistics hub requires the government to issue preferential policies, such as 
supportive trade policies, tax policies and talent policies (Xu \& Tong, 2018). In addition, the construction of Chongqing inland international logistics hub needs to strengthen policy guidance, establish and improve the corresponding supervision system, and supervise, restrict and standardize the construction of inland international logistics hubs, and carry out the whole process monitoring in three stages(as shown in Figure 3).

\subsection{Improve Infrastructure Construction}

Although Chongqing has become the only national central city in 12 inland provinces with the conditions of railways, highways, waterways and aviation coordinated transport and river-sea coordinated transport, the promotion of the Free Trade Zone, and the construction of various logistics infrastructures are relatively backward. Therefore, Chongqing inland international logistics hub needs to constantly improve the logistics base and build an efficient logistics system. At the financial level, investment in logistics infrastructure should be increased and foreign investment should be actively introduced. At the infrastructure level, first, speed up the construction of the road network, improve the railway infrastructure, and let it support more transportation of products. Second, standardize the construction of the entire air cargo facility. At the same time, the long-term planning of logistics development should be formulated, and the limited funds should be planned rationally. By referring to the logistics infrastructure of Rotterdam Port, the logistics infrastructure that conforms to the characteristics of Chongqing Free Trade Zone can be constructed, so as to obtain greater results in a short time and with less investment.

\subsection{Strengthen the Construction of Information Platform}

The application of modern information technology is also one of the main supporting points of the logistics industry. Logistics informatization can reduce operating costs and achieve the purpose of increasing economic benefits. Taking Rotterdam port as an example, the application of EDI technology and the use of unmanned automation systems in this port has greatly reduced labor costs, thus achieving a steady increase in revenue (Chen, 2017). Therefore, the construction of Chongqing inland international logistics hub needs to do a good job of informatization, use modern logistics technology (as shown in Figure 4) to improve competitiveness. Under the premise that the level of informatization is

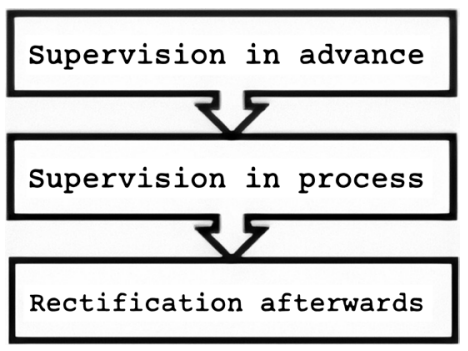

Figure 3. Supervision process of Chongqing inland international logistics hub construction. 


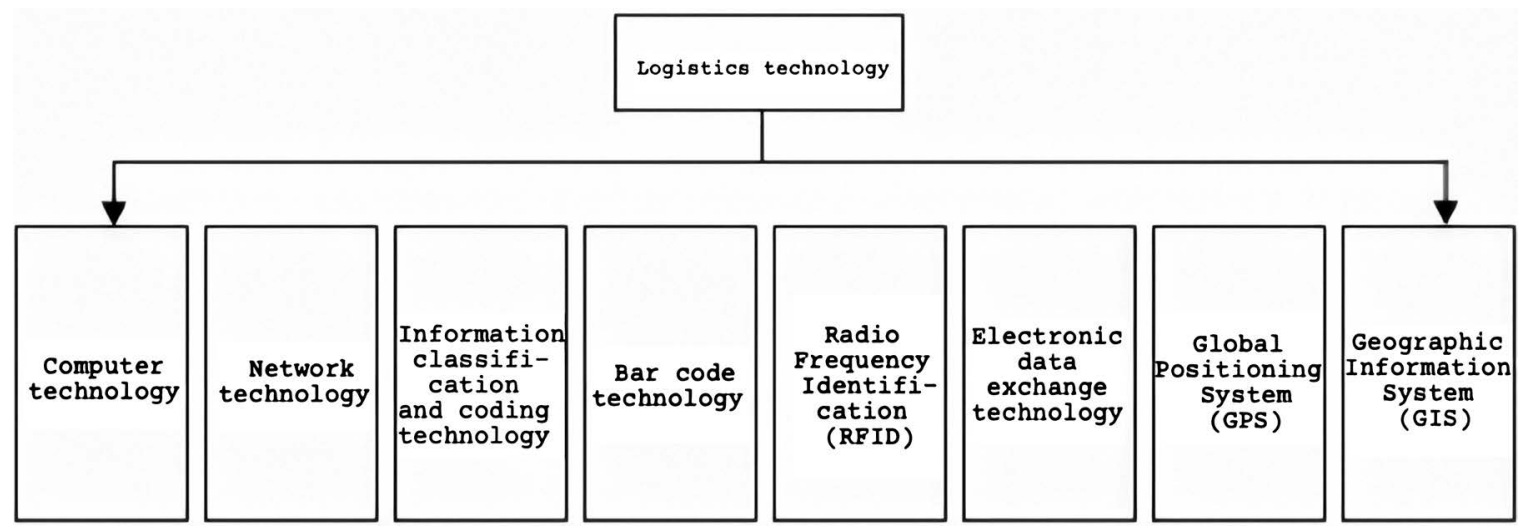

Figure 4. Technology required for modern logistics.

well guaranteed, we should strengthen the construction of logistics information platform, so that logistics information can be exchanged and shared on the information platform, accurate tracking of logistics information can be achieved (Li, 2015), all aspects of logistics can be organically combined to provide guarantee for reducing logistics costs, and should promote the establishment of intermodality standard system, improve the operation mechanism of international intermodality supervision center, integrate regulatory resources and optimize the regulatory process. In this way, it can show the powerful advantages of international logistics hub, such as information exchange of collection and distribution, information interaction, visual monitoring and so on, so that the technical level of logistics can greatly enhanced.

\subsection{Reserve Sufficient Professional Logistics Talents}

The key to building an inland international logistics hub under the framework of Chongqing Free Trade Zone lies in talents. First, it is necessary to strengthen the training and communication of internal staff, speed up the training of existing employees, improve their management, technology and business capabilities, find and tap talents from the inside, and improve endogenous power; second, it is urgent to introduce and cultivate a number of high-level scientific research and education institutions to train a large number of high-quality talents for the construction of Chongqing inland international logistics hub; third, it is necessary to actively introduce a large number of high-quality talents with rich practical experience in modern logistics, information services, operation supervision, risk prevention and control, who are familiar with multiple languages and international practices, and to break the salary limit and provide talent support for the construction of Chongqing inland international logistics hub under the framework of Free Trade Zone (Wang \& Chen, 2018).

\section{Shortcomings of the Article}

The shortcomings of the article are that there are few studies and analyses on the construction of Chongqing inland international logistics hub, so there are cer- 
tain difficulties in collecting and sorting out the reference and relevant data, which makes the foundation of the research not very solid. At the same time, the construction of the inland international logistics hub is a very comprehensive project, involving various factors. It is difficult to consider these factors in the research of this article, which requires continuous improvement on this basis.

\section{Conclusion}

To sum up, there are still many aspects to be improved in the construction of inland international logistics hub under the framework of Chongqing Free Trade Zone, such as the scattered logistics infrastructure, the low level of logistics information platform construction, and the shortage of professional logistics talents. Therefore, under the premise of the development of Free Trade Zone, it is hoped that Chongqing can seize the historical opportunity, recognize its advantages, reflect on its existing problems, learn from the successful experience of Rotterdam Port in the Netherlands, plan top level design, strengthen policy support and guidance, improve infrastructure construction, strengthen information platform construction, and reserve sufficient professional logistics talents, truly make the inland international logistics hub bigger and stronger, and form an important inland international logistics hub radiating the whole southwest region and driving the rapid economic development of Chongqing.

\section{Founding}

Supported by 2016 Social Science Planning and Cultivation Project Research on the Development Mode and Path of Inland International Logistics Center under the Framework of Chongqing Free Trade Zone, (2016PY42) and the Central University Basic Research Business Expense Project (SWU1909314).

\section{Conflicts of Interest}

The authors declare no conflicts of interest regarding the publication of this paper.

\section{References}

Chen, G. (2017). Successful Development Model and Enlightenment of Foreign Typical Port Logistics. Foreign Economic and Trade Practice, No. 5, 89-92.

Chen, L. (2019). Exploration on Development of Core Area of Chongqing International Logistics Hub. Journal of Chengdu Normal University, 35, 66-69.

Deng, C. (2017). Analysis of the Economic Development Experience and Model of Typical Ports in Europe and Asia-Taking Rotterdam Ports, Singapore Port and Taiwan Port as Examples. Industry and Technology Forum, 16, 89-90.

Hu, W. D. (2018). Analysis of the Current Situation and Countermeasures of Chongqing Intelligent Logistics Construction. Journal of Chongqing Radio \& TV University, 30, 31-35.

Li, G. (2017). The Third Batch of Semi-annual Reports of Free Trade Zone: The Dividends Are Gradually Released, and There Are More Than 60,000 Newly Registered 
Enterprises. 21st Century Business Herald, 2017-10-19 (008).

Li, H. L. (2015). The Influence of Free Trade Zone on Port Logistics in Fujian Province. Logistics Engineering and Management, 37, 36-37.

Wang, S., \& Chen, J. J. (2018). Analysis of the Development Experience of Rotterdam Free Trade Port in the Netherlands. Hainan Today, No. 7, 20-23.

Xu, R. H., \& Tong, L. H. (2018). Development Model and Enlightenment of Foreign Port Logistics. International Business Accounting, No. 5, 45-49. 